\title{
Evaluasi Kinerja Dosen oleh Mahasiswa Berbasis Online pada STMIK Pesat Nabire
}

\author{
Gunawan Prayitno ${ }^{1 *}$, Ester Ayuk Pusyita ${ }^{2}$ \\ Teknik Informatika, STMIK Pesat Nabire \\ Papua, Indonesia \\ sailor.jc@gmail.com, esterayukstmikpesat@gmail.com
}

\begin{abstract}
ABSTRAK - Evaluation of lecturer performance by students is one element of assessment in carrying out study program accreditation. Evaluation of lecturer performance by students at STMIK Pesat Nabire is less effective and efficient because it still uses paper as a questionnaire given to students before the Semester Final Examination is held. From planning to evaluating the results of a completed questionnaire that takes a long time and often miscalculates in getting the evaluation results, the expense of printing the questionnaire using paper also requires a lot of money. The purpose of this study was to create an online-based student evaluation system for lecturers using google form so that it is more effective and efficient. The results of the lecturer evaluation can be used by the head of the study program in evaluating the performance of the lecturers as a whole so that it becomes the basis for decision making in the followup to improve lecturer performance by correcting the weaknesses of the lecturers appropriately and measurably.
\end{abstract}

Keywords: Lecturer Performance Evaluation, STMIK Pesat Nabire, Google Form, Study Program

ABSTRAK - Evaluasi kinerja dosen oleh mahasiswa adalah salah satu unsur penilaian dalam melaksakan akreditasi program studi. Evaluasi kinerja dosen oleh mahasiswa di STMIK Pesat Nabire kurang efektif dan efesien karena masih mengunakan kertas sebagai angket yang diberikan kepada mahasiswa sebelum Ujian Akhir Semester dilaksanakan. Dari perencanaan sampai evaluasi hasil dari angket yang sudah terisi membutuhkan waktu yang lama dan sering terjadi kesalahan perhitungan dalam mendapatkan hasil evaluasi, pengeluaran biaya untuk mencetak angket mengunakan kertas juga membutuhkan biaya yang tidak sedikit. Tujuan dari penelitian ini adalah membuat sebuat sistem penilaian evaluasi dosen oleh mahasiswa berbasis online yaitu mengunakan Google Form sehingga lebih efektif dan efesien. Hasil dari evaluasi dosen dapat dipergunakan oleh ketua program studi dalam mengevaluasi kinerja dosen secara keseluruhan sehingga menjadi dasar dalam pengambilan keputusan dalam tindak lanjut peningkatan kinerja dosen dengan memperbaiki kelemahan dosen secara tepat dan terukur.

Kata Kunci: Evaluasi Kinerja Dosen, STMIK Pesat Nabire, Google Form, Program Studi

\section{PENDAHULUAN}

Kinerja dosen pada perguruan tinggi adalah perilaku yang nyata dari prestasi kerja dalam diri seseorang dalam melaksanakan tugasnya dalam pelaksanaan tridharma perguruan tinggi. Kinerja dosen adalah bagi terpenting dari perguruan tinggi dalam mewujudkan visi dan misi di STMIK Pesat Nabire yang telah ditetapkan dalam rapat senat inistitusi. Penilaian kinerja dosen adalah suatu proses dalam sebuah lembaga dalam melaksanakan penilaian dan evaluasi kinerja dosen. Penilaian kinerja dosen yang dilaksanakan di STMIK Pesat Nabire dilakukan dengan fungsi pengawasan terhadap kinerja dosen yang berarti penilaian kinerja dosen merangkap kegiatan dalam fungsi pengawasan dalam melaksanakan fungsi dosen dalam melaksanakan tridharma perguruan tinggi yaitu pendidikan, pengajaran dan pengabdian ke masyarakat.

Penelitian yang diadakan yang dilaksanakan oleh Try Hartiti Retnowati, dkk [1] dimana penelitian masih dilaksanakan secara manual yang dilaksanakan dalam 3 tahun yaitu tahun pertama (2017) dilakukan pengembangan instrumen yang akurat dan terpercaya, panduan penskoran, dan penentuan standar. Tahun kedua (2018) dilakukan uji coba penilaian kinerja dosen, produk awal aplikasi komputer, panduan pelaksanaan penilaian, dan panduan pemanfaatan hasil penilaian. Tahun ketiga (2019) dilakukan penilaian kinerja dosen, contoh pemanfaatan hasil penilaian, dan validasi aplikasi komputer didapatkan kesimpulan sebaiknya instrumen penilaian kinerja dosen, pedoman penskoran, dan standar capaian kinerja dosen dapat menjadi acuan penilaian kinerja dosen [1], pada penelitian yang dilaksanakan yang dilaksanakan oleh Thomas Brian [2] dimana penelitian evaluasi kinerja dosen sudah berbasis web dimana evaluasi kinerja dosen mengunakan bahasa pemrograman PHP dimana metode penelitiannya mengunakan model waterfall dimana kesimpulan yang didapatkan adalah sistem aplikasi kinerja dosen ini dapat mempercepat proses perhitungan nilai dan laporan.

Penilaian kinerja dosen oleh mahasiswa merupakan hal terpenting dalam mengukur kepuasan mahasiswa dalam pembelajaran yang dilaksanakan oleh dosen. Pengukuran tingkat kepuasan mahasiswa terhadap layanan pengajaran yang dilaksanakan oleh dosen disajikan dengan beberapa pertanyaan atau pernyataan 
melalui angket yang diberikan oleh mahasiswa untuk diisi sebelum Ujian Akhir Semester. Pengukuran tingkat kepuasan mahasiswa ini kemudian dimasukkan ke dalam Microsoft Excel untuk mendapatkan hasil dari evaluasi yang dilaksanakan. Pengukuran evaluasi dosen oleh mahasiswa ini membutuhkan biaya yang mahal karena harus mencetak angket sesuai jumlah mahasiswa dan membutuhkan waktu dan tenaga dalam pelaksanaanya.

Manfaat dari pengukuran tingkat kepuasan mahasiswa terhadap kinerja dosen dalam pendidikan berbasis online ini dapat menyelasaikan permasalahan biaya akibat dari pemakaian kertas dan juga waktu pelaksanaan dari perencanaan sampai hasilnya membutuhkan waktu yang singkat.

\section{METODOLOGI}

Evaluasi pembelajaran dapat digunakan sebagai upaya dosen dalam menciptakan pembelajaran yang efektif dan efesien dalam meningkatkan hasil belajar [3].

\section{A. Evaluasi Proses Pembelajaran}

Sasaran evaluasi proses pembelajaran adalah pelaksanaan maupun pengelolaan kegiatan belajar dan mengajar untuk memperoleh pemahaman tentang strategi belajar, metode mengajar dan media belajar yang dimanfaatkan dosen dalam melakukan kegiatan belajar mengajar baik sikap, minat dan kebiasaan belajar mahasiswa.

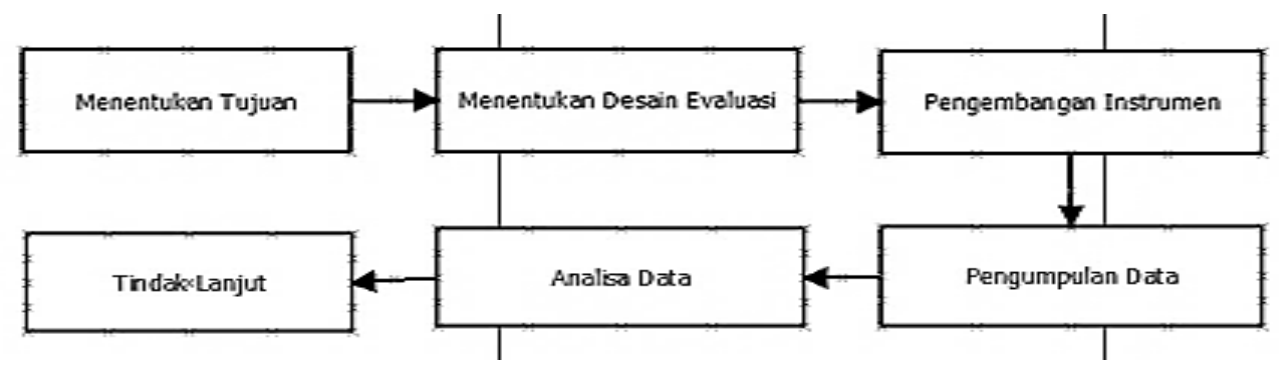

Gambar 1. Tahapan Pelaksanaan Evaluasi Proses Pembelajaran

\section{1) Menentukan Tujuan}

Tujuan evaluasi proses pembelajaran dapat dirumuskan dalam bentuk pernyataan atau pertanyaan. Secara umum tujuan evaluasi proses pembelajaran yang dilaksanakan dosen berfungsi sebagai berikut: (1) apakah dosen telah menyusun dan mengembangkan SAP (Satuan Acara Pembelajaran), Silabus perkuliahan maupun bandout materi pembelajaran, (2). Apakah dosen memiliki kemampuan, penyampaian materi, penguasaan materi kuliah, manajemen kelas, maupun metode pembelajaran. (3) kemampuan dosen dalam melaksanakan hubungan atau interaksi dengan mahasiswa dan (4) evaluasi terhadap hasil belajar dan hubungan antara soal dan materi pembelajaran [4].

\section{2) Menentukan Desain Evaluasi}

Desain evaluasi proses pembelajaran mencakup rencana evaluasi proses dan pelaksana evaluasi. Rencana evaluasi proses pembelajaran berbentuk matriks dengan kolom-kolom yang berisi: nomor urut, informasi yang dibutuhkan, indikator, metode yang mencakup teknik dan instrumen, responden dan waktu. Selanjutnya pelaksana evaluasi proses adalah dosen mata kuliah yang bersangkutan.

\section{3) Pengembangan Instrumen}

Instrumen evaluasi proses pembelajaran untuk memperoleh informasi deskriptif dan/atau informasi judgemental dapat berwujud (1) Lembar pengamatan untuk mengumpulkan informasi tentang kegiatan belajar mahasiswa dalam mengikuti pembelajaran yang dilaksanakan oleh dosen dapat digunakan oleh dosen sendiri atau oleh mahasiswa untuk saling mengamati, dan (2) Kuesioner yang harus dijawab oleh mahasiswa berkenaan dengan strategi pembelajaran yang dilaksanakan dosen, metode dan media pembelajaran yang digunkan oleh dosen, minat, persepsi mahasiswa tentang pembelajaran untuk suatu materi pokok sajian yang telah terlaksana.

\section{4) Pengumpulan Data}

Pengumpulan data atau informasi dilaksanakan secara obyektif dan terbuka agar diperoleh informasi yang dapat dipercaya dan bermanfaat bagi peningkatan mutu pembelajaran. Pengumpulan data atau informasi dilaksanakan pada setiap akhir pelaksanaan pembelajaran untuk materi sajian berkenaan dengan satu kompetensi dasar dengan maksud dosen dan mahasiswa memperoleh gambaran menyeluruh tentang pelaksanaan pembelajaran yang telah dilaksanakan untuk pencapaian penguasaan satu kompetensi dasar.

Dalam melaksanakan penelitian ini, metode pengumpulan dilaksanakan dengan studi pustaka yaitu dengan mencatatkan informasi yang relevan dengan masalah yang diteliti dengan mengumpulkan dari sumber-sumber pustaka seperti buku, jurnal penelitian dan internet.

\section{5) Analisis Data}

Analisis dan interpretasi hendaknya dilaksanakan setelah data maupun informasi dikumpulkan. Analisis berwujud deskripsi hasil evalusi berkenaan dengan proses pembelajaran yang telah terlaksana; sedang interpretasi merupakan penafsiran terhadap deskripsi hasil analisis proses pembelajaran. Analisis dan 
interpretasi dilakukan secara bersama-sama oleh dosen dan mahasiswa agar hasil evaluasi dapat segera diketahui dan dipahami oleh dosen dan mahasiswa sebagai bahan dan dasar memperbaiki pembelajaran selanjutnya.

Dalam melaksanakan analisis data, penelitian ini menggunakan metode incremental. Metode ini dipecahkan menjadi beberapa bagian, adapun beberapa bagian tersebut adalah sebagai berikut:

a. Requirement; adalah proses tahapan awal yang analisis kebutuhan.

b. Specification; adalah proses spesifikasi dimana menggunakan analisis kebutuhan sebagai acuannya.

c. Architecture Design; adalah tahap selanjutnya, perancangan software yang terbuka agar dapat diterapkan sistem pembangunan per-bagian pada tahapan selanjutnya.

d. Implementation/ Code; setelah melakukan proses desain selanjutnya ada pengkodean.

e. Testing; merupakan tahap pengujian dalam model ini.

f. Tindak lanjut; merupakan kegiatan menindak lanjuti hasil analisis dan interpretasi. Dalam evaluasi proses pembelajaran tindak lanjut pada dasarnya berkenaan dengan pembelajaran yang akan dilaksanakan selanjutnya dan evaluasi pembelajarannya. Pembelajaran yang akan dilaksanakan selanjutnya merupakan keputusan tentang upaya perbaikan pembelajaran yang akan dilaksanakan sebagai upaya peningkatan mutu pembelajaran; sedang tindak lanjut evaluasi pembelajaran berkenan dengan pelaksanaan dan instrumen evaluasi yang telah dilaksanakan mengenai tujuan, proses dan instrumen evaluasi proses pembelajaran [5].

\section{6) HASIL DAN PEMBAHASAN}

\section{A. Tahap Requirement}

Tahap pertama yang dilaksanakan adalah tahap requirement, pada tahap ini kita perlu analisis sistem yang berjalan pada sistem manual dimana tolak ukur kinerja dosen ditentukan dalam kemampuan dosen dalam melaksanakan metode belajar yang dilakukan di kelas. Penilaian kinerja dosen ini dilaksanakan oleh program studi dengan memberikan angket kepada mahasiswa untuk diisi kemudian dianalisa sehingga dapatkan penilaian kuantitatif terhadap kinerja dosen. Angket evaluasi kinerja dosen ini diberikan kepada mahasiswa sebelum ujian akhir semester dilaksanakan, untuk menggantikan penilaian kinerja dosen secara manual ke dalam sistem berbasis online sehingga mempermudah penilaian program studi terhadap kinerja dosen maka diperlukan perangkat keras dan perangkat lunak dalam pembuatan aplikasi evaluasi dosen oleh mahasiswa.

\section{B. Tahap Specification}

Untuk evaluasi kinerja dosen dibutuhkan perangkat keras dan perangkat lunak sehingga dapat dikomunikasikan maupun dihubungkan setiap fungsi sistem ke dalam sistem yang saling mendukung sehingga terintegrasi antara satu dengan lainnya [6].

Adapun kebutuhan perangkat keras dan perangkat lunak adalah 1). Perangkat Keras; yang digunakan adalah Personal Computer (PC) dengan spesifikasi: Processor Intel Core i3-8130U, RAM 4GB DDR4, HDD 1TB, ODD DVDRW, Grafik Integrated, Konektivitas Wi-Fi, Ukuran Layar 21.5 Inch FHD, dan All-in-One 200 G3. 2). Perangkat Lunak; yang digunakan adalah Sistem Operasi Windows 10 Pro, Google Form, dan Modzilla Firefox.

\section{Tahap Architecture Design}

Dalam architecture design pada penelitian ini mengunakan metode perancangan Unified Modeling Language (UML). UML adalah bahasa yang digunakan dalam standar industri dalam merancang, visualisasi dan dokumentasi perangkat lunak [7].

1) Use Case Diagram

Use case diagram menjelaskan hubungan satu atau beberapa aktor dengan sistem informasi yang digunakan. Dalam use case diagram kita bisa mengetahui siapa dan fungsi siapa saja yang ada dalam sistem [8].

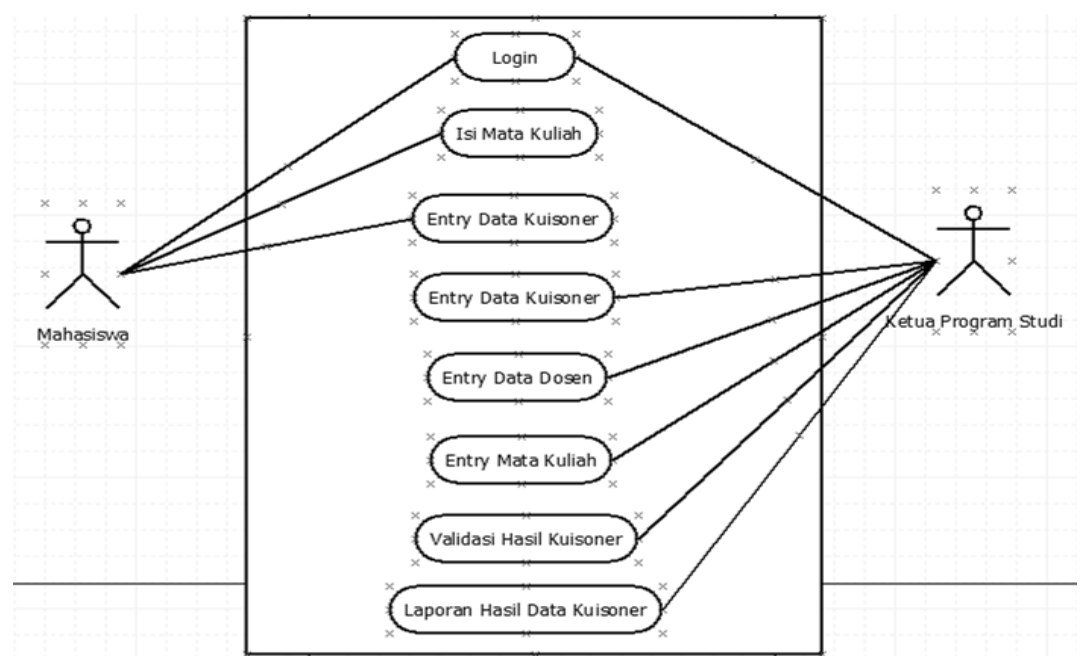

Gambar 2. Use Case Diagram 
Aliran informasi pada penelitian ini dapat dilihat pada Gambar 2 dimana mahasiswa melakukan evaluasi online dengan mengisi entry data mahasiswa maupun mengisi mata kuliah, dimana mahasiswa harus terlebih dahulu login sebelum masuk ke dalam sistem. Sedangkan ketua program studi dapat menginput data kuisoner, data dosen, data mata kuluah, melihat hasil kusioner dan laporan data kuisoner dengan terlebih dahulu login ke dalam sistem.

\section{2) Activity Diagram}

Gambar 3 menjelaskan aktivitas aliran kerja mahasiswa ke dalam sistem pada perangkat lunak. Sementara pada Gambar 4 menjelaskan aktivitas aliran kerja ketua program studi ke dalam sistem pada perangkat lunak.

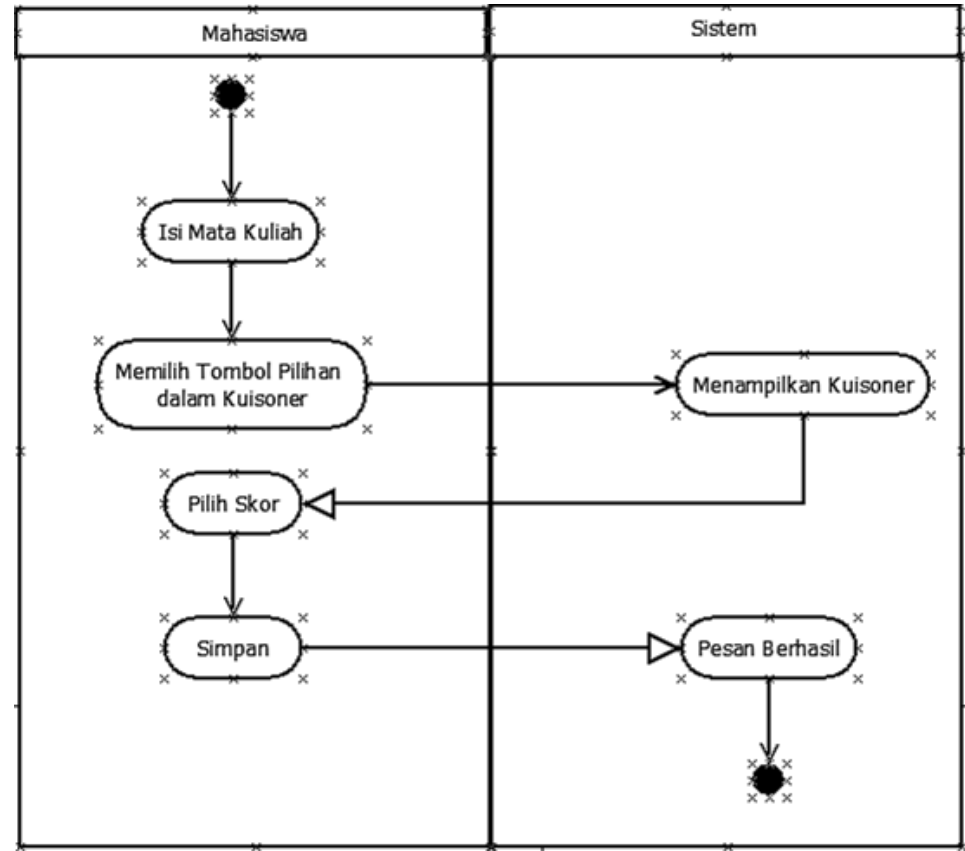

Gambar 3. Activity Diagram Isi Data Kuisoner

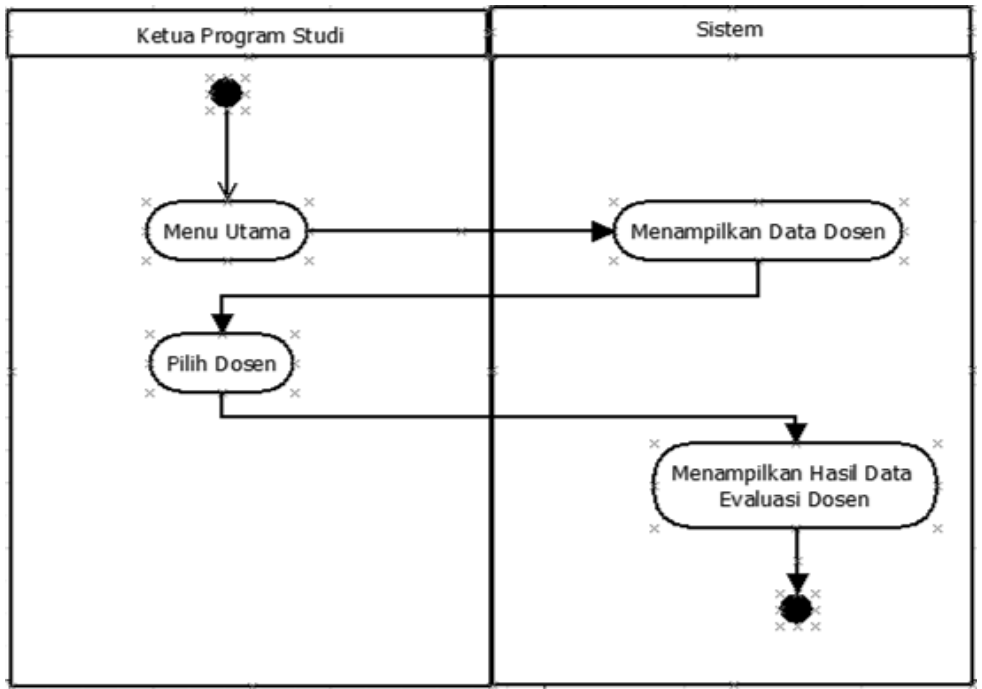

Gambar 4. Activity Diagram Melihat Hasil Evaluasi

\section{Tahap Implementasi}

Google form adalah peralatan yang digunakan dalam memberikan kesempatan bagi mahasiswa dalam mengevaluasi kinerja dosen dalam berbagai tempat, dimanapun mahasiswa berada dimana persyaratannya mahasiswa wajib memiliki komputer dan handphone. Adapun pertanyaan dalam evaluasi kinerja dosen oleh mahasiswa dapat dilihat pada Gambar 5 dibawah ini [9]. Gambar 5 menjelaskan pengisian kuisoner oleh responden mahasiswa dan daftar pertanyaan yang harus dijawab oleh mahasiswa dalam mengevaluasi dosen. 


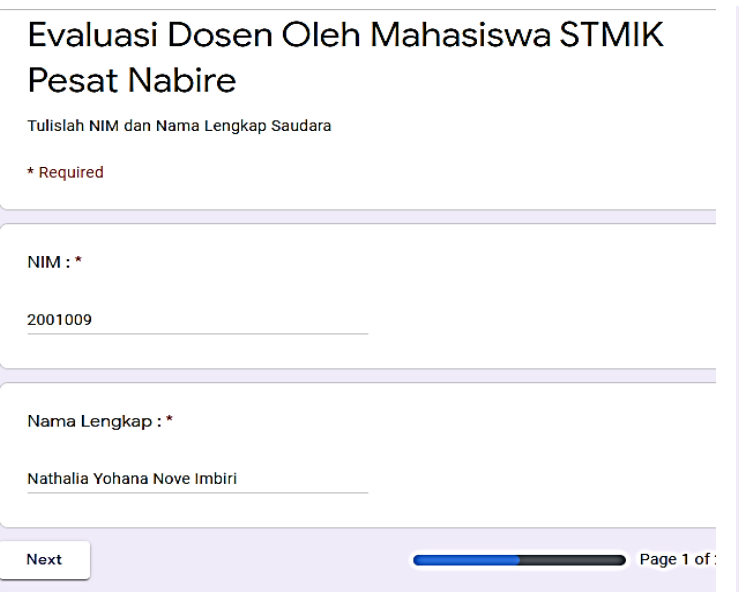

\section{Evaluasi Dosen Oleh Mahasiswa STMIK Pesat Nabire \\ * Required}

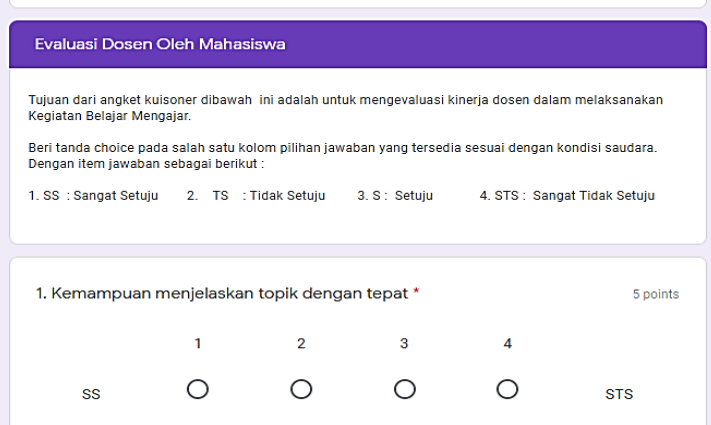

Gambar 5. Form Identitas Responden dan Evalusi Dosen oleh Mahasiswa

\section{E. Tahap Testing}

Test atau pengujian ini mengunaka Skala Likert yang melibatkan calon pengguna untuk manfaat penerapan, setiap calon pengguna dalam hal ini mahasiswa akan diberikan lembar kuesioner untuk memberikan tanggapan mengenai aplikasi. Hasil kuesioner diperoleh dari 20 pengguna sistem yaitu mahasiswa. Setelah kuesioner diisi oleh responden, kemudian kuesioner tersebut dihitung untuk mengetahui jumlah Sangat Setuju (SS), Setuju (S), Kurang Setuju (KS), dan Tidak Setuju (TS). Berikut adalah rekap hasil kuesionernya. Untuk mendapatkan hasil persentase yang dapat dilihiat pada tabel di bawah ini [10].

Tabel 1. Kuisoner Mahasiswa

\begin{tabular}{|c|c|c|c|c|c|c|}
\hline \multirow[t]{2}{*}{ No } & \multirow[t]{2}{*}{ Pertanyaan } & \multicolumn{4}{|c|}{ Jumlah Responden } & \multirow{2}{*}{$\begin{array}{l}\text { Total } \\
\text { Responden }\end{array}$} \\
\hline & & SS & $S$ & KS & TS & \\
\hline 1 & $\begin{array}{l}\text { Apakah aplikasi evaluasi dosen mengunakan Google Form dapat } \\
\text { membantu saudara melakukan evaluasi dosen dalam proses } \\
\text { mengajar di kelas? }\end{array}$ & 15 & 5 & 0 & 0 & 20 \\
\hline 2 & $\begin{array}{l}\text { Apkah aplikasi Google Form ini memudahkan saudara dalam } \\
\text { melaksanaka evaluasi dosen? }\end{array}$ & 10 & 8 & 1 & 1 & 20 \\
\hline 3 & $\begin{array}{l}\text { Apakah pertanyaan dan pernyataan dalam survey telah mewakili } \\
\text { keinginan suadara dalam mengevaluasi dosen? }\end{array}$ & 8 & 8 & 2 & 2 & 20 \\
\hline 4 & $\begin{array}{l}\text { Bagaimana pendapat saudara tentang kemudahan pengunaan } \\
\text { aplikasi Google Form dalam mengevaluasi dosen? }\end{array}$ & 9 & 11 & 0 & 0 & 20 \\
\hline \multirow[t]{2}{*}{5} & Apakah sistem ini mudah diakses oleh perangkat handphoe? & 8 & 12 & 0 & 0 & 20 \\
\hline & Jumlah & 50 & 44 & 3 & 3 & \\
\hline
\end{tabular}

Pada Tabel 1 menjelaskan bahwa setelah kuesioner diisi, kemudian kuesioner tersebut dihitung untuk mendapatkan nilai persentasenya dengan rumus:

jumlah pilihan jawaban SS,S,KS, atau TS jumlah keseluruhan Jawaban $\times 100$

Berdasarkan Tabel 1 maka persentase dari 20 reseponden memilih Sangat Setuju adalah $58 \%$, responden memilih Setuju $39 \%$, responden yang memilih Kurang Setuju adalah $2 \%$ dan responden memilih Tidak Setuju adalah $1 \%$.

\section{7) KESIMPULAN}

Berdasarkan perancangan dan implementasi sistem evaluasi dosen oleh mahasiswa disimpulkan bahwa dengan adanya aplikasi ini dapat mempermudah mahasiswa dalam menilai kinerja dosen dan bagi program studi sendiri bisa menjadi rujukan dalam tindak lanjut dalam memperbaiki kinerja dosen. Dari hasil pengujian dengan mengunakan metode survey diperoleh hasil yang sangat memuaskan dalam mengunakan sistem ini dimana yang menyatakan sangat setuju $58 \%$ dan setuju adalah $39 \%$ dan kurang setuju sebesar 2 persen dan tidak setuju sebesar $1 \%$, hal ini menunjukan bahwa evaluasi dosen mengunakan Google Form ini telah diterima dengan baik oleh mahasiswa.

\section{8) DAFTAR PUSTAKA}

[1] S. Trie Hartiti Retnowati, Djemari Mardapi, Badrun Kartowagiran, "Model Evaluasi Kinerja Dosen: Pengembangan Instrumen Untuk Mengevaluasi Kinerja Dosen Trie," J. Penelit. dan Eval. Pendidik., vol. 21, no. 5, 2017. 
[2] T. Brian, “Aplikasi Evaluasi Kinerja Dosen Berbasis Web pada Program Studi Pendidikan Informatika Universitas Trunojoyo Madura," Edutic - Sci. J. Informatics Educ., vol. 3, no. 2, pp. 69-75, 2017, doi: 10.21107/edutic.v3i2.2926.

[3] D. Ayuningtyas, P. Henry, and A. Wedi, "Aplikasi Web Evaluasi Proses Pembelajaran dengan Pendekatan Assessmen As Learning," Jktp, vol. 1, no. 1, pp. 77-84, 2018.

[4] A. S. dan H. Indrawat, "Peningkatan Hasil Belajar Mata Kuliah Manajemen Agribisnis Melalui Pemberian Hand Out pada Mahasiswa Jurusan Manajemen Fakultas Ekonomi Universitas Riau," vol. 9, no. 3, pp. 239-254, 2007.

[5] K. Yuliawan, "Algoritma Sequential Search dalam Kamus Bahasa Inawatan Berbasis Android," J. Mediat., vol. 4, no. 1, p. 35, 2021, doi: 10.26858/jmtik.v4i1.19727.
[6] D. W. Nugraha, "Software Requirement dalam Membangun Sistem Informasi Publik," Majalah Ilmiah Mektek, pp. 138-147, 2011.

[7] H. WidodoPrabowo Pudjo, "Mengunakan UML," Bandung: Informatika, 2011.

[8] Y. Heriyanto, "Perancangan Sistem Informasi Rental Mobil Berbasis Web Pada PT.APM Rent Car," J. Intra-Tech, vol. 2, no. 2, pp. 64-77, 2018.

[9] H. Husein, "Penggunaan Google Form sebagai Alat Penilaian Kinerja Dosen di Prodi PGMI Uniska Muhammad Arsyad Al Banjari," J. Pendidik. Dasar Islam, vol. 8, no. 1, pp. 40-50, 2016.

[10] E. Suwandi, F. H. Imansyah, and H. Dasril, "Analisis Tingkat Kepuasan Menggunakan Skala Likert pada Layanan Speedy yang Bermigrasi ke Indihome," J. Tek. Elektro, p. 11, 2018. 